Article

\title{
Structural Features of Sulfated Glucuronomannan Oligosaccharides and Their Antioxidant Activity
}

\author{
Weihua Jin ${ }^{1}$ (D), Langlang Ren ${ }^{1}$, Bing Liu ${ }^{1}$, Quanbin Zhang ${ }^{2,3, *}$ and Weihong Zhong ${ }^{1, *}$ \\ 1 College of Biotechnology and Bioengineering, Zhejiang University of Technology, Hangzhou 310023, China; \\ jinweihual@zjut.edu.cn (W.J.); 15700084451@163.com (L.R.); liubing19950108@163.com (B.L.) \\ 2 Laboratory of Experimental Marine Biology, Institute of Oceanology, Chinese Academy of Sciences, \\ Qingdao 266071, China \\ 3 Center for Ocean Mega-Science, Chinese Academy of Sciences, Qingdao 266000, China \\ * Correspondence: qbzhang@qdio.ac.cn (Q.Z.); whzhong@zjut.edu.cn (W.Z.);
} Tel.: +86-532-82898703 (Q.Z.); +86-571-88320739 (W.Z.)

Received: 20 July 2018; Accepted: 16 August 2018; Published: 21 August 2018

\begin{abstract}
Glucuronomannan oligosaccharides (Gs) were derived from fucoidan, which was extracted from the brown alga Sargassum thunbergii. Sulfated glucuronomannan oligosaccharides (SGs) were obtained by the sulfation of Gs. NMR techniques were used to reveal that the order of sulfation was Man-C6 > Man-C4 > Man-C1R > GlcA-C3 > Man-C3 > GlcA-C2. Finally, the antioxidant activities (hydroxyl radical scavenging activity, superoxide radical scavenging activity, reducing power and DPPH radical scavenging activity) of Gs and SGs were determined. The findings showed that the higher the degree of polymerization, the better the activity, except for the hydroxyl radical scavenging activity. In addition, the higher the sulfate content, the lower the activities for the reducing power and DPPH radical scavenging activity. Opposite results were found for the superoxide radical scavenging activity. Finally, compared with fucoidan, most Gs and SGs had higher antioxidant activity, suggesting that they might be good candidates for antioxidants.
\end{abstract}

Keywords: glucuronomannan oligosaccharides; sulfation; antioxidant activity

\section{Introduction}

Oligosaccharides play crucial roles in a wide range of biological processes, such as cellular communication, pathogenesis and prebiotic functions [1-5]. For this reason, they are also being developed for new drugs. In addition, they have advantages over polysaccharides, which cannot pass through barriers in the body, even cell membrane. Thus, more research on oligosaccharides is being conducted.

In this study, glucuronomannan oligosaccharides obtained from degradation of fucoidan that was extracted from the brown alga Sargassum thunbergii. Glucuronomannan is one of the main backbones of fucoidan, which had a variety of biological activities, including antioxidant, antitumour and neuroprotective activities [6-11]. In addition, glucuronomannan has many branches, including sulfate group, fucopyranoside and fucooligopyranoside [12-14]. However, there has been little research on the activities of glucuronomannan oligosaccharides or sulfated glucuronomannan oligosaccharides.

Sulfation is important since it changes a polysaccharides' antioxidant, antiviral, antitumour activities, etc. [15-18]. It was found that the inhibitory effects of fucans on both coagulation and cell proliferation decreased with decreasing sulfate content [15]. It was found that oversulfated fucoidan reduced the proliferation of U937 cells in a dose-dependent manner whereas native fucoidan showed no such activity [19]. Chevolot et al. [20] reported that anticoagulant activities of fucoidan were also dependent on sulfate contents. 
Thus, we tried to elucidate the patterns of sulfation using the sulfur trioxide-pyridine method in this study. In addition, we also tried to illustrate the effects of sulfate content and degree of polymerization on antioxidant activities.

\section{Results}

\subsection{Preparation of Sulfated Glucuronomannan Oligosaccharides}

By changing the molar ratios of glucuronomannan oligosaccharides (G2, G4 and G6) to sulfur trioxide-pyridine, glucuronomannan oligosaccharides with different degree of sulfation were obtained. Then, the amounts were confirmed by ESI-MS. The results (Figures S1-S8) are summarized in Table 1. It was shown that $\mathrm{G} 2$ had two different fractions (G2S1, which was $\operatorname{GlcAMan}\left(\mathrm{SO}_{3} \mathrm{H}\right)_{3-6}$ with high degree of sulfation, and G2S2, which was GlcAMan $\left(\mathrm{SO}_{3} \mathrm{H}\right)_{1-3}$ with low degree of sulfation). G4 had three different fractions (G4S1, which was $\mathrm{GlcA}_{2} \mathrm{Man}_{2}\left(\mathrm{SO}_{3} \mathrm{H}\right)_{8-11}$ with high degree of sulfation, G4S2, which was $\mathrm{GlcA}_{2} \mathrm{Man}_{2}(\mathrm{SO} 3 \mathrm{H})_{5-9}$ with medium degree of sulfation, and G4S3, which was $\mathrm{GlcA}_{2} \mathrm{Man}_{2}(\mathrm{SO} 3 \mathrm{H})_{1-5}$ with low degree of sulfation). G6 had three different fractions (G6S1, which was $\mathrm{GlcA}_{3} \mathrm{Man}_{3}(\mathrm{SO} 3 \mathrm{H})_{8-15}$ with high degree of sulfation, G6S2, which was $\mathrm{GlcA}_{3} \mathrm{Man}_{3}(\mathrm{SO} 3 \mathrm{H})_{4-10}$ with medium degree of sulfation, and G6S3, which was $\mathrm{GlcA}_{3} \mathrm{Man}_{3}(\mathrm{SO} 3 \mathrm{H})_{1-6}$ with low degree of sulfation).

Table 1. The chemical compositions of glucuronomannan oligosaccharides and their sulfated fractions.

\begin{tabular}{cc}
\hline Sample & Chemical Compositions \\
\hline G2S1 & GlcAMan $\left(\mathrm{SO}_{3} \mathrm{H}\right)_{3-6}$ \\
G2S2 & GlcAMan $\left(\mathrm{SO}_{3} \mathrm{H}\right)_{1-3}$ \\
G2 & GlcAMan \\
G4S1 & $\mathrm{GlcA}_{2} \mathrm{Man}_{2}\left(\mathrm{SO}_{3} \mathrm{H}\right)_{8-11}$ \\
G4S2 & $\mathrm{GlcA}_{2} \mathrm{Man}_{2}\left(\mathrm{SO}_{3} \mathrm{H}\right)_{5-9}$ \\
G4S3 & $\mathrm{GlcA}_{2} \mathrm{Man}_{2}\left(\mathrm{SO}_{3} \mathrm{H}\right)_{1-5}$ \\
G4 & $\mathrm{GlcA}_{2} \mathrm{Man}_{2}$ \\
G6S1 & $\mathrm{GlcA}_{3} \mathrm{Man}_{3}\left(\mathrm{SO}_{3} \mathrm{H}\right)_{8}-15$ \\
G6S2 & $\mathrm{GlcA}_{3} \mathrm{Man}_{3}\left(\mathrm{SO}_{3} \mathrm{H}\right)_{4-10}$ \\
G6S3 & $\mathrm{GlcA}_{3} \mathrm{Man}_{3}\left(\mathrm{SO}_{3} \mathrm{H}\right)_{1-6}$ \\
G6 & $\mathrm{GlcA}_{3} \mathrm{Man}_{3}$ \\
\hline
\end{tabular}

\subsection{Structural Analysis of Sulfated Glucuronomannan Oligosaccharides by ESI-CID-MS/MS}

To elucidate the structural features of sulfated glucuronomannan oligosaccharides, ESI-CID-MS/MS was performed. The ESI-CID-MS/MS spectrum of the ion at $m / z 296.991(-2)$ ([GlcAMan $\left.\left(\mathrm{SO}_{3} \mathrm{H}\right)_{3}-2 \mathrm{H}\right]^{2-}$ ) is shown in Figure 1. Only one ion at $m / z 257.009$ (-2), corresponding to $\left[\mathrm{GlcAMan}\left(\mathrm{SO}_{3} \mathrm{H}\right)_{2}-2 \mathrm{H}\right]^{2-}$, was derived from the loss of sulfur trioxide $(-80 \mathrm{Da}) . \mathrm{MS} / \mathrm{MS} / \mathrm{MS}$ (Figure 1) was performed to confirm the sulfation pattern. The ions at $m / z 435.022(-1)$ and $217.029(-2)$ were also derived from the loss of sulfur trioxide $(-80 \mathrm{Da})$, which was confirmed by the presence of an ion at $m / z$ 96.965. The absence of an ion at $m / z 355$ [GlcAMan-H] ${ }^{-}$proved that the last sulfate group was relatively stable. The ion at $m / z 259.025$ indicated that the sulfate group was substituted at the Man residue, which was confirmed by the presence of an ion at $m / z 175.033$ ( $\mathrm{Y}_{1}$-type ion), suggesting that the GlcA residue was not sulfated. The characteristic ion at $m / z 199.001\left({ }^{0,2}\right.$ X-type ion) indicated that the linkage of the GlcA residue and the Man residue was $1 \rightarrow 2$, which was consistent with a previous study [13]. On the other hand, it also indicated that the sulfation group was substituted at C4 or $\mathrm{C} 6$ of the Man residue, because the formation of ${ }^{0,2} \mathrm{X}$ originated from the $\mathrm{C} 3$ hydroxy group [21]. In addition, the presence of fragment ions at $m / z 168.989$ ( ${ }^{0,3}$ X-type ion) and 138.977 ( ${ }^{0,4} \mathrm{X}$-type ion) indicated that the sulfation was at C6 of the Man residue. No ions at $m / z 255$ and 273 were found. Thus, it was concluded that it was difficult to determine the precise location of sulfation. 


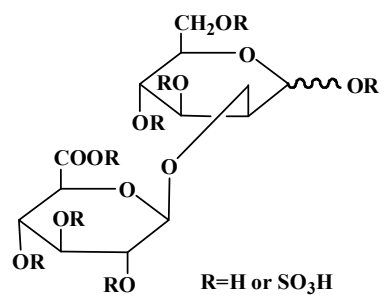

(a)

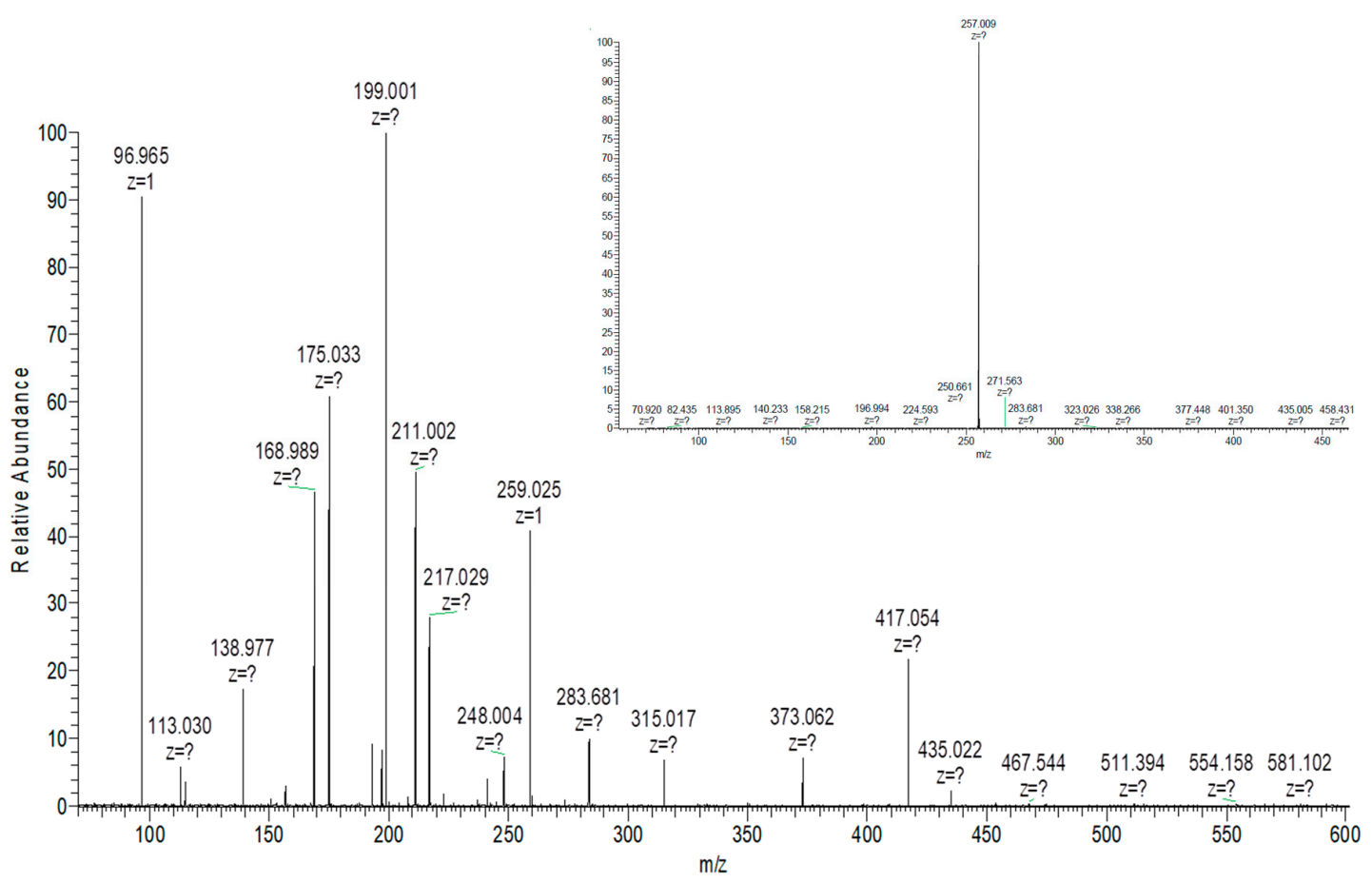

(b)

Figure 1. (a) The chemical structure of disaccharide GlcAMan $\left(\mathrm{SO}_{3} \mathrm{H}\right)_{3}$. (b) Negative-ion mode electrospray ionization in tandem with collision-induced dissociation tandem mass (ESI-CID-MS/MS) spectrum of the ion at $m / z 296.991$ (-2), corresponding to GlcAMan $\left(\mathrm{SO}_{3} \mathrm{H}\right)_{3}$ and ESI-CID-MS/MS/MS spectrum of the ion at $m / z 257.009(-2)$, corresponding to GlcAMan $\left(\mathrm{SO}_{3} \mathrm{H}\right)_{2}$.

Finally, NMR was performed to elucidate the precise location of sulfation. Figure 2 shows the DEPTQ spectra of the glucuronomannantetramer (G4) and its low sulfated fraction (G4S3). The chemical shifts of G4 and G6 were shown in Table S1. Comparison of these two DEPTQ spectra shows that: (1) The reversal peaks of the Man residue C6 at the reducing end (C6R) and the non-reducing end (C6) were missing, while another new reversal peak with a chemical shift of $67.5 \mathrm{ppm}$ was found (another reversal peak was overlapped, which was confirmed by Figure 3), suggesting that the Man residue at C6 was sulphated. (2) The intensity of the peaks of the Man residues $\mathrm{C} 4$ at the non-reducing end $(\mathrm{C} 4)$ and the reducing end $(\mathrm{C} 4 \mathrm{R})$ decreased, indicating that the Man residues $\mathrm{C} 4$ at the non-reducing end (C4) and the reducing end (C4R) were partially sulphated. (3) The intensity of the peak of the Man residue $\mathrm{C} 1$ at the reducing end (C1R) was relatively unmodified, indicating that the Man residue $\mathrm{C} 1$ at the reducing (C1R) was not sulfated. To further confirm the precise location of sulfation, we compared the ${ }^{1} \mathrm{H}-\mathrm{NMR}$ spectra of the glucuronomannantetramer (G4), and its low sulfated fraction (G4S3) (Figure 2). It was shown that (1) the chemical shifts of the Man residue $\mathrm{H} 1$ at the reducing end $(5.14 \mathrm{ppm})(\mathrm{H} 1 \mathrm{R})$ and the non-reducing end $(5.28 \mathrm{ppm})(\mathrm{H} 1)$ and the GlcA residue $\mathrm{H} 1$ at the reducing $(4.37 \mathrm{ppm})\left(\mathrm{H}^{\prime} 1\right)$ and the non-reducing end $(4.33 \mathrm{ppm})\left(\mathrm{H}^{\prime} 1 \mathrm{~N}\right)$ were the same, indicating that the Man residues $\mathrm{C} 3$ at the reducing end (C3R) and the non-reducing end 
(C3) and the GlcA residues $\mathrm{C} 2$ at the reducing end $\left(\mathrm{C}^{\prime} 2\right)$ and the non-reducing end $\left(\mathrm{C}^{\prime} 2 \mathrm{~N}\right)$ were not sulfated. These findings were also confirmed by the presence of the Man residues $\mathrm{H} 2$ at the reducing (3.91 ppm) (H2R) and the non-reducing ends (4.05 ppm) (H2) and the GlcA residue $\mathrm{H} 2$ at the reducing (3.23 ppm) $\left(\mathrm{H}^{\prime} 2\right)$ and the non-reducing ends (3.28 ppm) $\left(\mathrm{H}^{\prime} 2 \mathrm{~N}\right)$; (2) In addition, the chemical shift of the GlcA residue $\mathrm{H} 3$ at the non-reducing end $(3.38 \mathrm{ppm})\left(\mathrm{H}^{\prime} 3 \mathrm{~N}\right)$ did not change, indicating that it was not sulfated. Moreover, the signal of $\mathrm{GlcA}_{2} \mathrm{Man}_{2}\left(\mathrm{SO}_{3} \mathrm{H}\right)_{5}$ was weak in the MS spectrum. In conclusion, the findings suggest that the order of sulfation might be Man-C6 $\approx$ Man-C6R > Man-C4 $\approx$ Man-C4R.

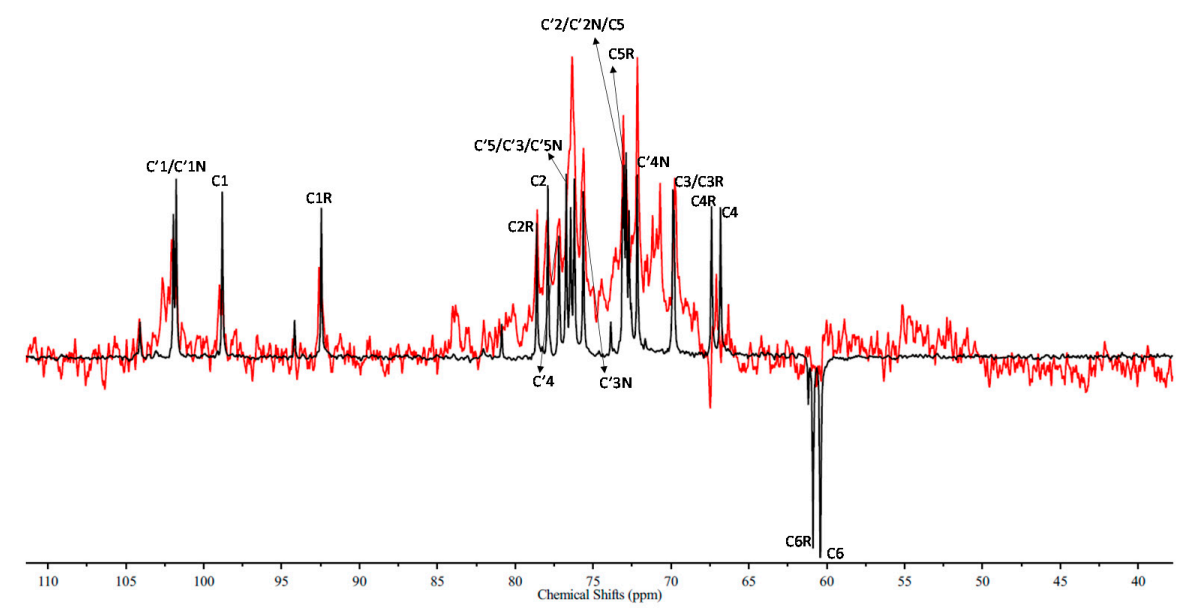

(a)

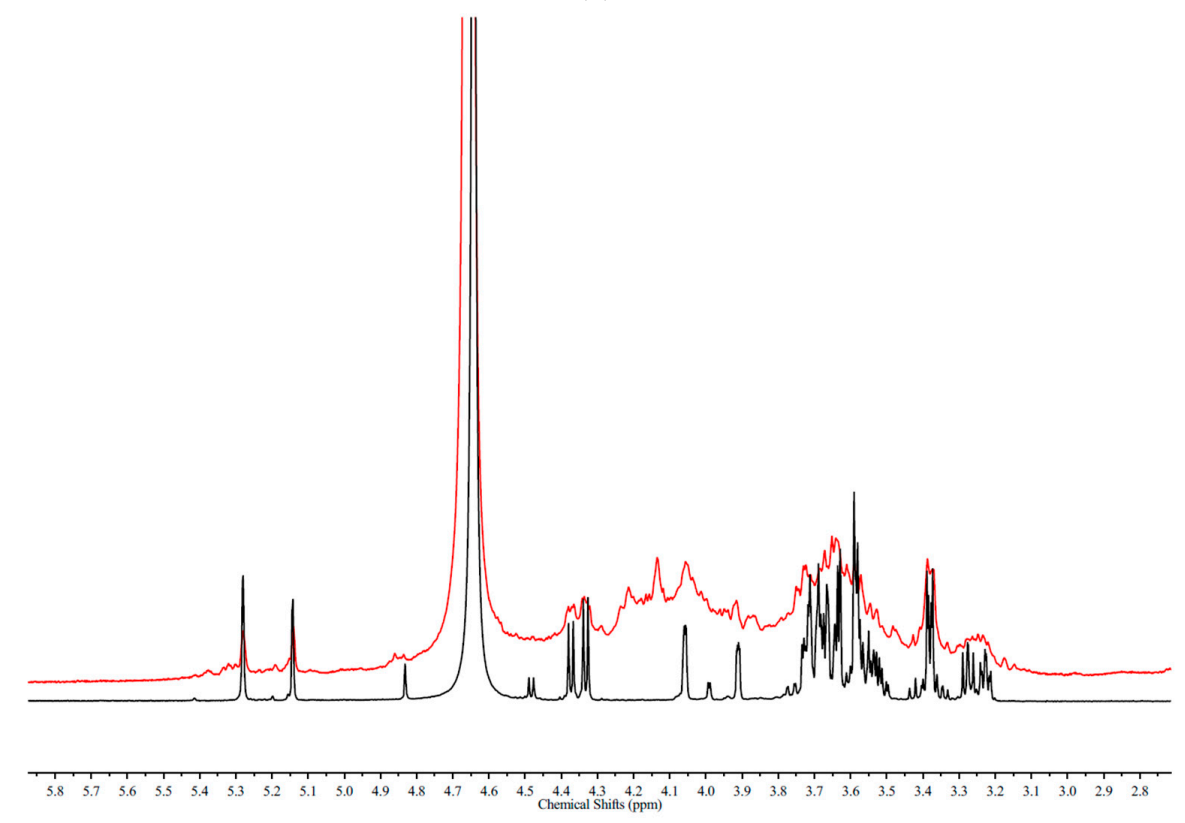

(b)

Figure 2. (a) The DEPTQ spectra and (b) ${ }^{1} \mathrm{H}-\mathrm{NMR}$ spectra of a glucuronomannan-tetramer (G4) and its low sulfated fraction (G4S3) (Red). 


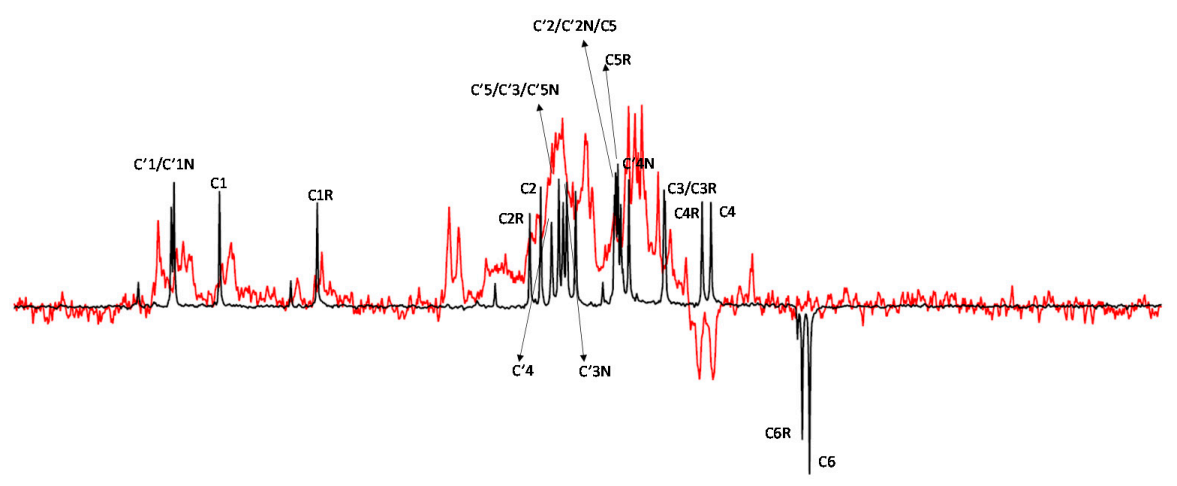

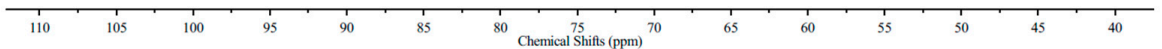

(a)

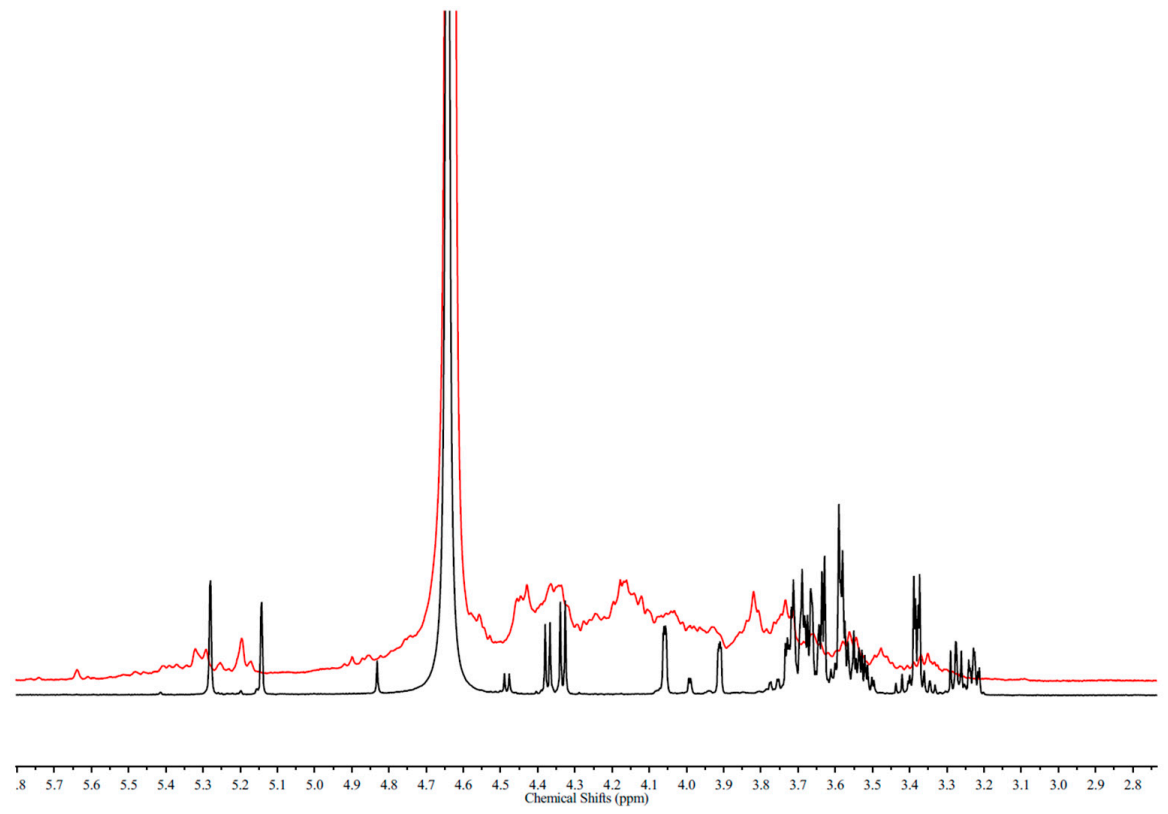

(b)

Figure 3. (a) The DEPTQ spectra and (b) 1H-NMR spectra of a glucuronomannan-tetramer (G4) and its medium sulfated fraction (G4S2) (Red).

The DEPTQ and ${ }^{1} \mathrm{H}-\mathrm{NMR}$ spectra of glucuronomannan-tetramer (G4) and its medium sulfation fraction (G4S2) were shown in Figure 3. A comparison of these two DEPTQ spectra (Figure 3a) shows that: (1) The reversal peaks of the Man residues C6 at the reducing (C6R) and the non-reducing end (C6) were missing, while another two new reversal peaks with chemical shifts of $67.6 \mathrm{ppm}$ and $66.7 \mathrm{ppm}$ appeared in the spectrum, suggesting that the Man residues at $\mathrm{C} 6$ were both sulfated. (2) The peaks of the Man residues $\mathrm{C} 4$ at the non-reducing end (C4) and the reducing end (C4R) were missing, indicating that the Man residues of $\mathrm{C} 4$ at the non-reducing end (C4) and the reducing end (C4R) were sulfated. (3) The peak of the Man residue $\mathrm{C} 1$ at the reducing (C1R) was missing, indicating that the Man residue of $C 1$ at the reducing (C1R) was sulfated. (4) There were three peaks with chemical shifts of $100.6 \mathrm{ppm}, 101.2 \mathrm{ppm}$ and $101.6 \mathrm{ppm}$, which were influenced by the sulfation of the GlcA residues $\mathrm{C} 3$ at the reducing end $\left(\mathrm{C}^{\prime} 3\right)$ and the non-reducing end $\left(\mathrm{C}^{\prime} 3 \mathrm{~N}\right)$. (5) Comparison with the DEPTQ spectra of G4S3 and G4S2 (Figure S9 in the Supplementary Materials), it was found that the Man residues $\mathrm{C} 3$ at the reducing end (C3R) and the non-reducing end (C3) were missing, indicating that they were sulfated. To further confirm the precise location of sulfation, the ${ }^{1} \mathrm{H}-\mathrm{NMR}$ spectra of the glucuronomannan-tetramer (G4) and its medium sulfation fraction (G4S3) were compared (Figure 3b). 
These ${ }^{1} \mathrm{H}-\mathrm{NMR}$ spectra show that: (1) The peak of the Man residue H1 at the reducing end (5.14 ppm) (H1R) was missing, indicating that it was sulfated, which was also confirmed by a new peak with a chemical shift of $5.64 \mathrm{ppm}$. (2) The chemical shifts of the GlcA residues $\mathrm{H} 1$ at the non-reducing end $\left(\mathrm{H}^{\prime} 1 \mathrm{~N}\right)$ and the reducing end $\left(\mathrm{H}^{\prime} 1\right)$ were unchanged. In addition, the peaks of the GlcA residues $\mathrm{H} 2$ at the non-reducing end $\left(\mathrm{H}^{\prime} 2 \mathrm{~N}\right)$ and the reducing end $\left(\mathrm{H}^{\prime} 2\right)$ were missing. Thus, it was suggested that the GlcA residues $\mathrm{H} 3$ at the non-reducing end $\left(\mathrm{H}^{\prime} 3 \mathrm{~N}\right)$ and the reducing end $\left(\mathrm{H}^{\prime} 3\right)$ were sulfated. (3) There were no peaks of the Man residues $\mathrm{H} 2$ at the non-reducing end (4.05 ppm) (H2) and the reducing end (3.91 ppm) (H2R), which were influenced by the sulfation of the Man residues $\mathrm{H} 1$ at the reducing end (H1R) and $\mathrm{H} 3$ at the reducing end (C3R) and the non-reducing end (C3). Consequently, it was concluded that the order of sulfation might be Man-C6 $\approx$ Man-C6R $>$ Man-C4 $\approx$ Man-C4R $>$ Man-C1R $>$ GlcA-C'3N $\approx$ GlcA-C'3 > Man-C3 $\approx$ Man-C3R.
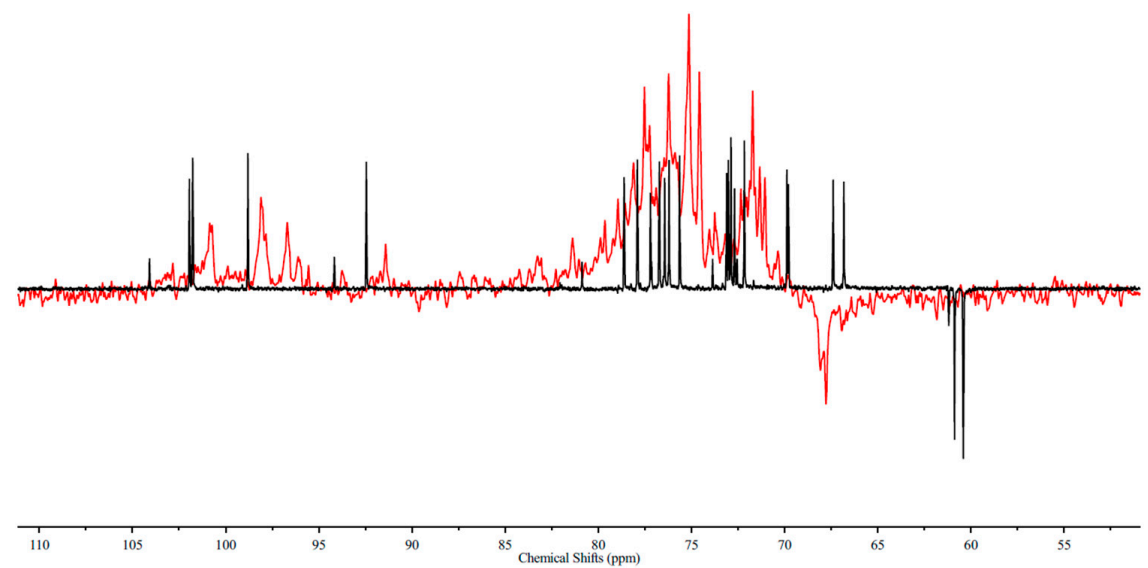

(a)

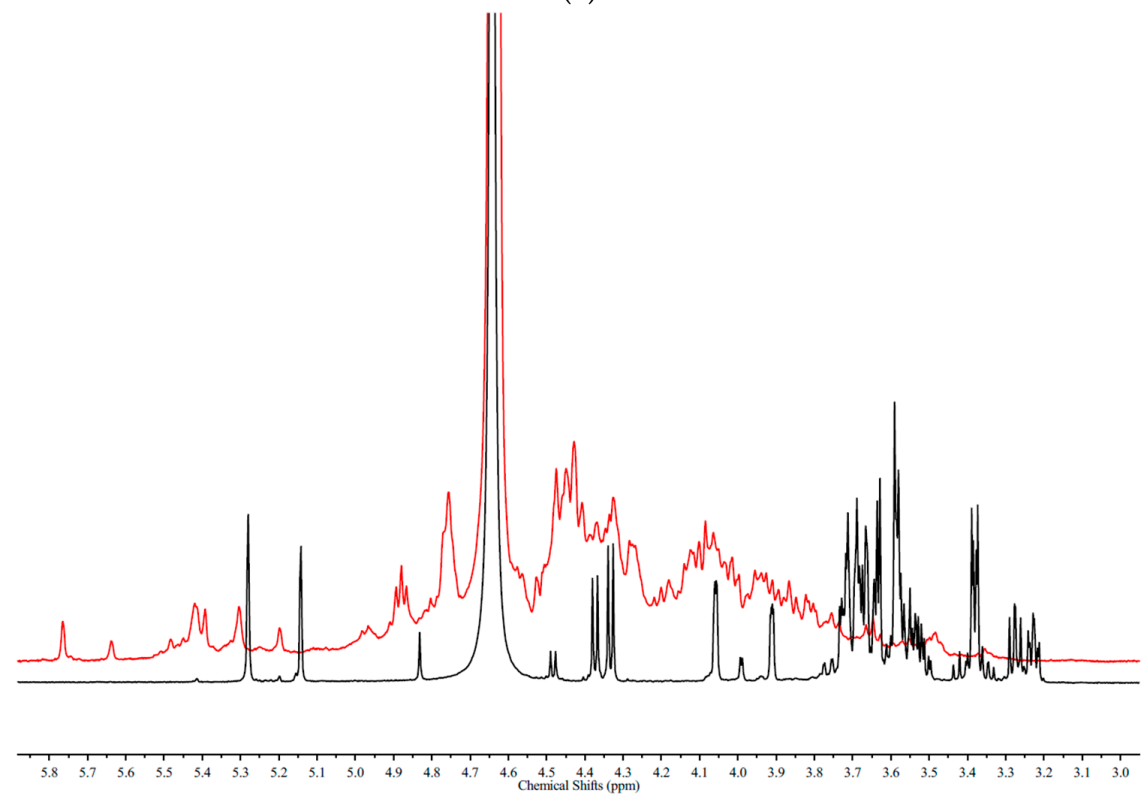

(b)

Figure 4. (a) The DEPTQ spectra and (b) 1H-NMR spectra of a glucuronomannan-tetramer (G4) and its high sulfated fraction (G4S1) (Red).

Figure 4 are the DEPTQ (a) and ${ }^{1} \mathrm{H}-\mathrm{NMR}$ (b) spectra of glucuronomannan-tetramer (G4) and its high sulfation fraction (G4S1). The spectra were relatively complicated. However, it was proposed that the order of sulfation might be Man-C6 $\approx$ Man-C6R $>$ GlcA-C'4N $>$ Man-C $\approx$ Man-C4R $>$ Man-C1R $>$ GlcA-C'3N $\approx$ GlcA-C'3 $>$ Man-C 2 Man-C3R $>$ GlcA-C'2N $\approx$ GlcA-C'2, based on the above results. 
Finally, we propose that the order of sulfation on glucuronomannan-oligomers is Man-C6 > GlcA-C4 > Man-C4 > Man-C1R > GlcA-C3 > Man-C3 > GlcA-C2.

\subsection{Antioxidant Activities of Glucuronomannan Oligosaccharides and Their Sulfated Fractions}

Four different assays (hydroxyl radical scavenging activity, superoxide radical scavenging activity, reducing power and DPPH radical scavenging activity) were conducted to investigate the effects of sulfate content and the degree of polymerization on antioxidant activities.

The hydroxyl radical scavenging assay (Figure 5A) demonstrated the ability of the samples to scavenge hydroxyl radical produced by the Fenton system. This assay showed that most samples exhibited hydroxyl radical scavenging activity in a concentration-dependent manner. Comparison with glucuronomannan oligosaccharides (G2, G4 and G6), G4 was the best, followed by G6, and G2 has the least hydroxyl radical scavenging activity. In terms of sulfate content, the activity was dependent on the degree of polymerization. The activity for $\mathrm{G} 6$ and its fractions was in the following order: G6 > G6S1 > G6S2 > G6S3, the activity for G4 and its fractions was G4 > G4S3 > G4S2 > G4S1, and the activity for G2 and its fractions was G2S2 > G2S1 > G2. Thus, we concluded that G4 and G4S3 showed the best activity, while fucoidan (the raw material of glucuronomannan oligosaccharides) showed only $30 \%$ activity at a concentration of $7 \mathrm{mg} / \mathrm{mL}$ [22]. Previous studies [23,24] have shown that there are two mechanisms responsible for scavenging hydroxyl radical: First is to inhibit the production of hydroxyl radical, and another is to remove the hydroxyl radical generated. The first mechanism is correlated with the ability of chelating metal ions, which depends on molecular weight, sulfate content and uronic acid content. Thus, we proposed that the activity of glucuronomannan oligosaccharides and their sulfated fractions was influenced by the sulfate content and the degree of polymerization in inhibiting the production of hydroxyl radical.

Although superoxide radical is a weak oxidant in most organisms, it can also be degraded continuously to produce new active reactive oxygen species (ROS), leading indirectly to the peroxidation of lipids and directly causing diseases such as arthritis and Alzheimer's disease [25,26]. For this reason, it was essential to investigate the effects of the sulfate content and the degree of polymerization on superoxide radical scavenging activity. Information on these effects might help to screen for novel drugs. Figure $5 \mathrm{~B}$ shows that a positive correlation exists between superoxide radical scavenging activity and the concentration of most samples. When compared with sulfated glucuronomannan oligosaccharides, the glucuronomannan oligosaccharides showed lower scavenging activity, indicating that sulfate was important for this activity. In addition, the higher the sulfate content, the better the superoxide radical scavenging activity. Similarly, the higher the degree of polymerization, the better the activity. When compared with fucoidan, whose activity was approximately $80 \%$ at a concentration of $50 \mu \mathrm{g} / \mathrm{mL}$ [22], glucuronomannan oligosaccharides and their sulfated fractions had lower superoxide radical scavenging activity.

The reducing power assay determines the reducing power using $\mathrm{Fe}^{3+} /$ ferricyanide and furnished an important index of potential antioxidant activity. Figure $5 \mathrm{C}$ shows that the reducing power increased with increasing concentration, displaying a linear correlation. Compared with glucuronomannan oligosaccharides, the result showed that the higher the degree of polymerization, the better the reducing-power. In terms of sulfate content, the results show that sulfated glucuronomannan oligosaccharides had lower reducing power. This phenomenon was opposite to the superoxide radical scavenging activity, except for G6S1. When compared with fucoidan (with an absorbance of approximately 0.1 at a concentration of $2.5 \mathrm{mg} / \mathrm{mL}$ ) [22], glucuronomannan oligosaccharides and their sulfated fractions showed higher reducing power.

Compared with other methods of evaluating antioxidant activities, the DPPH radical scavenging assay is a time-saving and rapid method and it is widely used for this reason. Most samples exhibited a positive correlation between the measured activity and the concentration of the polysaccharides (Figure 5D). When compared with glucuronomannan oligosaccharides, it was shown that the higher the degree of polymerization, the better the activity. In terms of the sulfate content, it was 
found that sulfated glucuronomannan oligosaccharides had lower DPPH radical scavenging activity. This phenomenon was the same with regards to reducing power but was opposite to superoxide radical scavenging activity, except for G6S1. When compared with low molecular weight fucoidan [27], whose activity was approximately $80 \%$ at a concentration of $7.0 \mathrm{mg} / \mathrm{mL}$, glucuronomannan oligosaccharides and their sulfated fractions have higher activity.
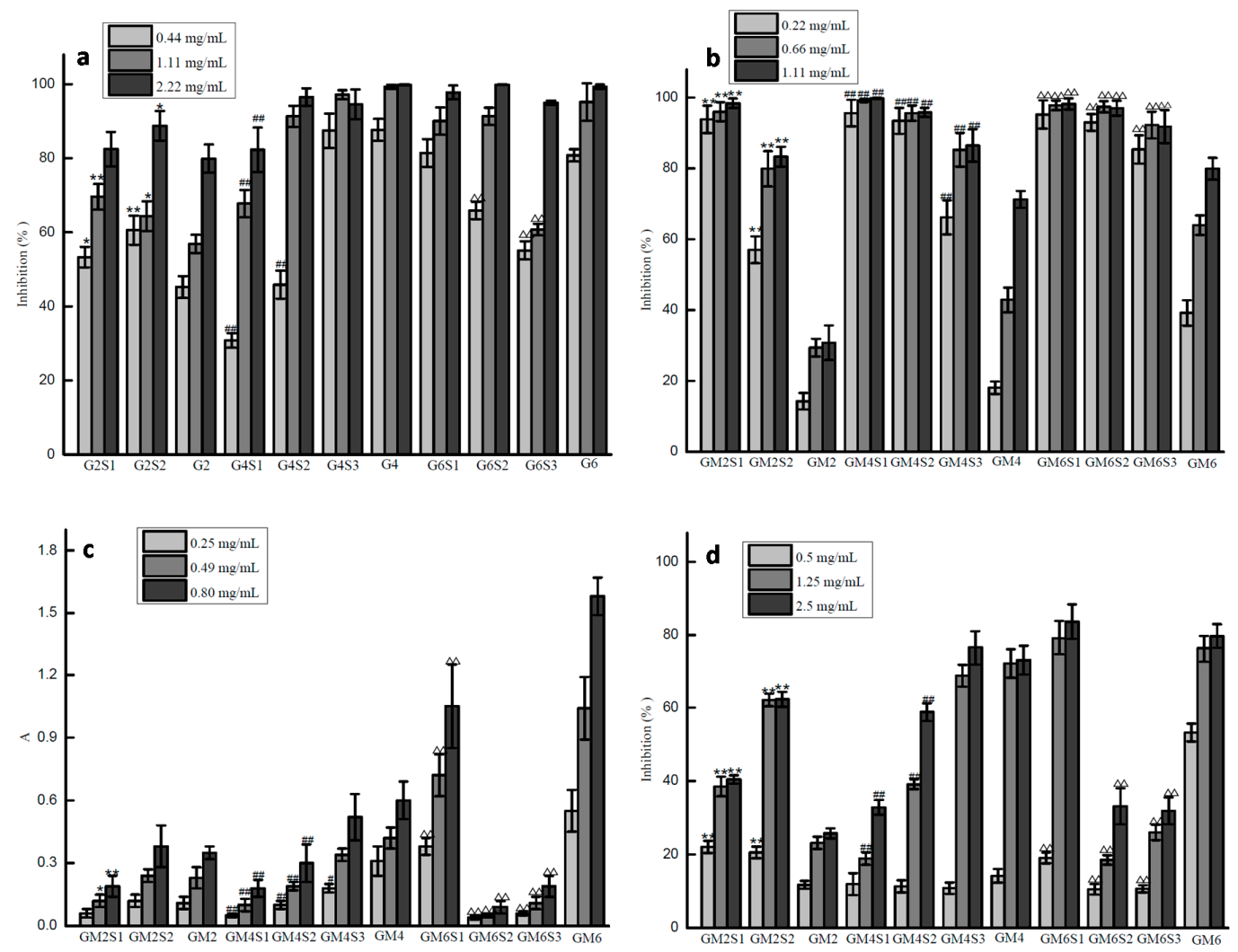

Figure 5. The scavenging effects of different glucuronomannan oligosaccharides and their sulfated fractions on hydroxyl radical (a), superoxide radical (b), reducing power (c) and DPPH free radical (d). Values are expressed as the mean $\pm \mathrm{SD}$ from three replicates. $\left({ }^{*} p<0.05\right.$ compared to the G2; ${ }^{* *} p<0.01$ compared to the G2; $\# p<0.05$ compared to the G4; \#\# $p<0.01$ compared to the G4; $\Delta p<0.05$ compared to the G6; $\Delta \Delta p<0.01$ compared to the G6).

\section{Discussion}

Glucuronomannan oligosaccharides (Gs) were derived from fucoidan, which was extracted from the brown alga Sargassum thunbergii. Sulfated glucuronomannan oligosaccharides (SGs) were obtained by the sulfation of Gs. Ten samples with different sulfate content and degree of polymerization were prepared to elucidate the structure-activity relationships between sulfated oligosaccharides and antioxidant activities, including hydroxyl radical scavenging activity, superoxide radical scavenging activity, reducing power and DPPH radical scavenging activity. It was shown that: (1) The glucuronomannan tetramer (G4) and the glucuronomannan hexamer (G6) had higher hydroxyl radical scavenging activities than their partial sulfate fractions and the glucuronomannan dimer (G2), while the activity of the glucuronomannan dimer (G2) was lower than that of its sulfated fractions at the concentrations of $0.44 \mathrm{mg} / \mathrm{mL}$ and $1.11 \mathrm{mg} / \mathrm{mL}$. Therefore, there was no correlation between sulfate content and degree of polymerization and hydroxyl radical scavenging activity. (2) With regards to the superoxide radical scavenging activity, the results show that the higher the degree of polymerization, the better the activity. Similarly, the higher the sulfate content, the better the activity. (3) For the reducing power and DPPH radical scavenging activities, similar trends of the superoxide radical 
scavenging activity occurred. The results also show that the higher the degree of polymerization, the better the activity. On the contrary, the higher the sulfate content, the lower the activity, except for G6S1. Therefore, it was concluded that the structure-activity relationship for different activities were different. In another word, there was no absolute correlation suitable for all structure-activity relationship of Gs and SGs. Further studies on the neuroprotective activity of sulfated oligosaccharides will be determined to elucidate their structure-activity relationship.

\section{Materials and Methods}

\subsection{Preparation of Glucuronomannan Oligosaccharides}

The brown alga Sargassum thunbergii was collected in Qingdao, China. The alga (100 g) was cut into pieces. Crude polysaccharide from Sargassum thunbergii was extracted with hot water ( $3 \mathrm{~L}$ ) for $4 \mathrm{~h}$. The aqueous solution was filtered with Celite and concentrated by rotary evaporator. Elimination of alginate was achieved using $20 \%$ ethanol in water with $\mathrm{MgCl}_{2}$. After removing the alginate, the supernatant was dialyzed, concentrated and precipiteted by ethanol. Glucuronomannan oligosaccharides were prepared according to a protocol modified from a previous study [13]. Briefly, crude polysaccharide was refluxed in $4 \%$ sulfuric acid aqueous solution $(60 \mathrm{mg} / \mathrm{mL})$ for $5 \mathrm{~h}$ and then neutralized with barium hydroxide after cooling to room temperature. The solution was centrifuged, and the supernatant was concentrated by rotary evaporator. The concentrated solution was fractionated using an activated carbon column $(2.6 \mathrm{~cm} \times 30 \mathrm{~cm})$ with water $(\mathrm{Y} 1)$ and $50 \%$ ethanol (Y2). Then, eluent Y2 was combined, concentrated and freeze-dried. Y2 (0.5 g) was separated on a Bio-Gel P-4 Gel column (Extra Fine, $<45 \mu \mathrm{M}, 2.6 \mathrm{~cm} \times 100 \mathrm{~cm}$ ) and then eluted with $0.5 \mathrm{M} \mathrm{NH}_{4} \mathrm{HCO}_{3}$ at a flow rate of $0.15 \mathrm{~mL} / \mathrm{min}$. Fractions were collected every $14 \mathrm{~min}$ per pipe after $27 \mathrm{~h}$. Glucuronomannan oligosaccharides (G2 stands for glucuronomannan dimer, G4 stands for glucuronomannan tetramer, and G6 stands for glucuronomannan hexamer) were collected and lyophilized. The yields of G2, G4 and G6 were $45.9 \%, 23.6 \%$ and $10.4 \%$, respectively.

\subsection{Preparation of Sulfated Glucuronomannan Oligosaccharides}

The sulfated glucuronomannan oligosaccharides were prepared according to a protocol modified from the previous study [28]. Oligomers (G2, G4 and G6) with different sulfur trioxide-pyridine were added to dimethylformamide (DMF) at room temperature for $24 \mathrm{~h}$, after which the solution was diluted, neutralized and concentrated. Then, the solution was desalted on a Sephadex G-10 column $(5 \mathrm{~cm} \times 50 \mathrm{~cm})$, and eluted with water. Finally, the sulfated glucuronomannan oligosaccharides were purified on a Bio-Gel P-4 Gel column (Extra Fine, $<45 \mu \mathrm{M}, 2.6 \mathrm{~cm} \times 100 \mathrm{~cm}$ ) and eluted with $0.5 \mathrm{M}$ $\mathrm{NH}_{4} \mathrm{HCO}_{3}$ at a flow rate of $0.15 \mathrm{~mL} / \mathrm{min}$.

\subsection{MS Analysis of Oligosaccharides}

ESI-MS and ESI-CID-MS/MS were performed on an LTQ ORBITRAP XL (Thermo Scientific, Waltham, MA, USA). The samples were dissolved in $\mathrm{CH}_{3} \mathrm{CN}-\mathrm{H}_{2} \mathrm{O}(1: 1, v / v)$. The solution was centrifuged, and the supernatant was analyzed. Mass spectra were registered in a negative ion mode at a flow rate of $5 \mu \mathrm{L} / \mathrm{min}$. The capillary voltage was set to $-3000 \mathrm{~V}$, and the cone voltage was set at $-50 \mathrm{~V}$. The source temperature was $80^{\circ} \mathrm{C}$, and the desolvation temperature was $150{ }^{\circ} \mathrm{C}$. The collision energy was optimized between 10 and $50 \mathrm{eV}$. All spectra were analyzed by Xcalibur.

\subsection{NMR Spectroscopy}

Oligosaccharides $(20 \mathrm{mg})$ were co-evaporated with deuterium oxide $(99.9 \%)$ twice before dissolving in deuterium oxide (99.9\%). 1D and 2D NMR spectra were recorded on a Bruker AVANCE III (Bruker BioSpin, Billerica, MA, USA) at $600 \mathrm{MHz}$ and $25^{\circ} \mathrm{C}$. 


\subsection{Investigation of Antioxidant Activity}

\subsubsection{The Activity of Scavenging Hydroxyl Radicals}

The ability of the samples to scavenge hydroxyl radical was determined according to a modified method [27]. Briefly, $2 \mathrm{mmol} / \mathrm{L}$ EDTA-Fe $(0.5 \mathrm{~mL})$, sodium phosphate buffer $(150 \mathrm{mM}, \mathrm{pH}=7.4$, $1 \mathrm{~mL}$ ), Safranine $\mathrm{T}$ (dissolved in above sodium phosphate buffer, $1 \mathrm{~mL}$ ), and $3 \% \mathrm{H}_{2} \mathrm{O}_{2}(1 \mathrm{~mL})$ were added sequentially into the solution $(1 \mathrm{~mL})$ with various concentrations of samples (First, the original concentrations of all samples were $25 \mathrm{mg} / \mathrm{mL}$. Then, they were diluted with different buffers). Then, the mixtures were incubated at $37^{\circ} \mathrm{C}$ for $30 \mathrm{~min}$, and the absorbance at $520 \mathrm{~nm}$ was measured. In the control, distilled water was substituted for sample and sodium phosphate buffer was substituted for $\mathrm{H}_{2} \mathrm{O}_{2}$. The scavenging effect (percentage) was calculated using the following equation: Scavenging effect $(\%)=A_{\text {sample }} / A_{\text {control }} \times 100$.

\subsubsection{The Activity of Scavenging Superoxide Radicals}

A superoxide radical assay was conducted according to a modified method [27]. Briefly, $0.5 \mathrm{~mL}$ nicotinamide adenine dinucleotide-reduced (NADH) $(0.0365 \%, w / v), 0.5 \mathrm{~mL}$ nitro blue tetrazolium (NBT) $(0.0246 \%, w / v)$, and $0.5 \mathrm{~mL}$ phenazine methosulfate (PMS) $(0.002 \%, w / v)$ were added sequentially into Tris- $\mathrm{HCl}$ buffer $(16 \mathrm{mmol} / \mathrm{L}, \mathrm{pH}=8.0)(3 \mathrm{~mL})$ with different concentrations of samples (First, the original concentrations of all samples were $25 \mathrm{mg} / \mathrm{mL}$. Then, they were diluted with different buffers). Then, the absorbance of the solutions at $560 \mathrm{~nm}$ was measured. In controls, Tris- $\mathrm{HCl}$ buffer was substituted for sample. The scavenging effect (percentage) was calculated using the following equation: Scavenging effect $(\%)=\left(1-\mathrm{A}_{\text {sample }} / \mathrm{A}_{\text {control }}\right) \times 100$.

\subsubsection{The Reducing Power Assay}

The reducing power assay was conducted according to a modified method [29]. Briefly, $1.25 \mathrm{~mL}$ of potassium ferricyanide $(1 \%, w / v)$ was added to the solution $(1 \mathrm{~mL})$ with different concentrations of samples (First, the original concentrations of all samples were $25 \mathrm{mg} / \mathrm{mL}$. Then, they were diluted with different buffers). Then, the mixtures were incubated at $50{ }^{\circ} \mathrm{C}$ for $20 \mathrm{~min}$. Later, $2.5 \mathrm{~mL}$ of trichloroacetic acid (TCA) $(10 \%, w / v)$ was added to the mixture to stop the reaction. Finally, $1.5 \mathrm{~mL}$ of $\mathrm{FeCl}_{3}(0.1 \%, w / v)$ was added, and the absorbance of the solutions at $700 \mathrm{~nm}$ was measured.

\subsubsection{DPPH Radical Scavenging Activity}

The DPPH free radical assay was based on a modified method [30]. Briefly, $1 \mathrm{~mL}$ of $0.1 \mathrm{mmol} \mathrm{L}^{-1}$ DPPH solution in ethanol was added to the solution $(3 \mathrm{~mL})$ with different concentrations of samples (dissolved in 50\% ethanol). Firstly, the original concentrations of all samples were $25 \mathrm{mg} / \mathrm{mL}$. Then, they were diluted with different buffers. The mixtures were then shaken vigorously and allowed to stand at room temperature for $20 \mathrm{~min}$. The absorbance at $517 \mathrm{~nm}$ was measured. As a control, the 50\% ethanol solution was substituted for sample. The scavenging effect (percentage) was calculated with the following equation: Scavenging effect $(\%)=\left(1-\mathrm{A}_{\text {sample }} / \mathrm{A}_{\text {control }}\right) \times 100$.

\subsection{Statistical Analysis}

All data are shown as the mean \pm standard deviation (SD). Significant differences between experimental groups were determined by one-way ANOVA, and differences were considered as statistically significant if $p<0.05$. All calculations were performed using SPSS 16.0 statistical Software.

\section{Conclusions}

ESI-MS with ESI-CID-MS/MS was performed to elucidate the structure of SGs. However, this technique failed because there were an insufficient number of A-type or X-type ions to indicate the linkages of the sulfation pattern. Therefore, NMR was performed, and this technique showed that the 
order of sulfation was Man-C6 $>$ Man-C4 $>$ Man-C1R $>$ GlcA-C3 $>$ Man-C3 $>$ GlcA-C2. The antioxidant activities of ten sulfated oligosaccahrides in four assays, i.e., hydroxyl radical scavenging activity, superoxide radical scavenging activity, reducing power and DPPH radical scavenging activity, were determined. It was shown that sulfate content and degree of polymerization represented different degrees of effects on the antioxidant activities. In addition, compared with fucoidan, most Gs and SGs molecules had higher activities in terms of hydroxyl radical scavenging activity, reducing power and DPPH radical scavenging, although superoxide radical scavenging activity was different. In conclusion, Gs and SGs might be good candidates for anti-oxidants.

Supplementary Materials: The following are available online at http:/ / www.mdpi.com/1660-3397/16/9/291/s1, Figure S1: Negative-ion mode ESI-MS spectrum of G2S1, Figure S2: Negative-ion mode ESI-MS spectrum of G2S2, Figure S3: Negative-ion mode ESI-MS spectrum of G4S1, Figure S4: Negative-ion mode ESI-MS spectrum of G4S2, Figure S5: Negative-ion mode ESI-MS spectrum of G4S3, Figure S6: Negative-ion mode ESI-MS spectrum of G6S1, Figure S7: Negative-ion mode ESI-MS spectrum of G6S2, Figure S8: Negative-ion mode ESI-MS spectrum of G6S3, Figure S9: The DEPTQ spectra of a glucuronomannan tetramer (G4), its low sulfated fraction (G4S3) and its medium sulfated fraction (G4S2), Table S1: The chemical shifts of G4 and G6.

Author Contributions: W.J. and Q.Z. were responsible for glucuromannan oligomers preparation; W.J., L.R., B.L. and W.Z. were responsible for sulfated glucuromannan preparation; W.J. performed the MS and NMR spectroscopy; W.J. L.R. and B.L. evaluated the antioxidant activity; All authors contributed to results, interpretation and approved the paper. W.J., Q.Z. and W.Z. wrote the original draft, supervised the research and revised the manuscript.

Funding: This study was supported by the National Natural Science Foundation of China (41506165).

Conflicts of Interest: The authors declare no conflict of interest. The funders had no role in the design of the study; in the collection, analyses, or interpretation of data; in the writing of the manuscript, and in the decision to publish the results.

\section{References}

1. Chen, R. Enzyme and microbial technology for synthesis of bioactive oligosaccharides: An update. Appl. Microbiol. Biotechnol. 2018, 102, 3017-3026. [CrossRef] [PubMed]

2. McCranie, E.K.; Bachmann, B.O. Bioactive oligosaccharide natural products. Nat. Prod. Rep. 2014, 31, 1026-1042. [CrossRef] [PubMed]

3. Chen, X.Y.; Wang, R.F.; Liu, B. An update on oligosaccharides and their esters from traditional Chinese medicines: Chemical structures and biological activities. Evid. Based Complement. Altern. Med. 2015, 2015, 512675. [CrossRef] [PubMed]

4. Dai, X.; Chang, P.; Li, X.; Gao, Z.; Sun, Y. The inhibitory effect of chitosan oligosaccharides on beta-site amyloid precursor protein cleaving enzyme 1 (BACE1) in HEK293 APPswe cells. Neurosci. Lett. 2018, 665, 80-85. [CrossRef] [PubMed]

5. Jeddou, K.B.; Bouaziz, F.; Helbert, C.B.; Nouri-Ellouz, O.; Maktouf, S.; Ellouz-Chaabouni, S.; Ellouz-Ghorbel, R. Structural, functional, and biological properties of potato peel oligosaccharides. Int. J. Biol. Macromol. 2018, 112, 1146-1155. [CrossRef] [PubMed]

6. Usov, A.I.; Bilan, M.I. Fucoidans-sulfatedd polysaccharides of brown algae. Russ. Chem. Rev. 2009, 78, 785-799. [CrossRef]

7. Li, B.; Lu, F.; Wei, X.; Zhao, R. Fucoidan: Structure and Bioactivity. Molecules 2008, 13, 1671-1695. [CrossRef] [PubMed]

8. Jiao, G.; Yu, G.; Zhang, J.; Ewart, H. Chemical Structures and Bioactivities of Sulfated Polysaccharides from Marine Algae. Mar. Drugs 2011, 9, 196-223. [CrossRef] [PubMed]

9. Fitton, J.H.; Stringer, D.N.; Karpiniec, S.S. Therapies from Fucoidan: An Update. Mar. Drugs 2015, 13, 5920-5946. [CrossRef] [PubMed]

10. Fitton, J.H. Therapies from Fucoidan; Multifunctional Marine Polymers. Mar. Drugs 2011, 9, 1731-1760. [CrossRef] [PubMed]

11. Pomin, V.H.; Mourão, P.A.S. Structure, biology, evolution, and medical importance of sulfated fucans and galactans. Glycobiology 2008, 18, 1016-1027. [CrossRef] [PubMed] 
12. Bilan, M.I.; Grachev, A.A.; Shashkov, A.S.; Kelly, M.; Sanderson, C.J.; Nifantiev, N.E.; Usov, A.I. Further studies on the composition and structure of a fucoidan preparation from the brown alga Saccharina latissima. Carbohydr. Res. 2010, 345, 2038-2047. [CrossRef] [PubMed]

13. Jin, W.; Wang, J.; Ren, S.; Song, N.; Zhang, Q. Structural analysis of a heteropolysaccharide from Saccharina japonica by electrospray mass spectrometry in tandem with collision-induced dissociation tandem mass spectrometry (ESI-CID-MS/MS). Mar. Drugs 2012, 10, 2138-2152. [CrossRef] [PubMed]

14. Wu, J.D.; Lv, Y.J.; Liu, X.X.; Zhao, X.L.; Jiao, G.L.; Tai, W.J.; Wang, P.P.; Zhao, X.; Cai, C.; Yu, G.L. Structural Study of Sulfated Fuco-Oligosaccharide Branched Glucuronomannan from Kjellmaniella crassifolia by ESI-CID-MS/MS. J. Carbohydr. Chem. 2015, 34, 303-317. [CrossRef]

15. Haroun-Bouhedja, F.; Ellouali, M.; Sinquin, C.; Boisson-Vidal, C. Relationship between Sulfate Groups and Biological Activities of Fucans. Thromb. Res. 2010, 100, 453-459. [CrossRef]

16. Karmakar, P.; Pujol, C.A.; Damonte, E.B.; Ghosh, T.; Ray, B. Polysaccharides from Padina tetrastromatica: Structural features, chemical modification and antiviral activity. Carbohydr. Polym. 2010, 80, 513-520. [CrossRef]

17. Mestechkina, N.M.; Shcherbukhin, V.D. Sulfated Polysaccharides and Their Anticoagulant Activity:A Review. Appl. Biochem. Microbiol. 2010, 46, 291-298. [CrossRef]

18. Jin, W.H.; Zhang, W.J.; Liang, H.Z.; Zhang, Q.B. The Structure-Activity Relationship between Marine Algae Polysaccharides and Anti-Complement Activity. Mar. Drugs 2016, 14, 3. [CrossRef] [PubMed]

19. Teruya, T.; Konishi, T.; Uechi, S.; Tamaki, H.; Tako, M. Anti-proliferative activity of oversulfated fucoidan from commercially cultured Cladosiphon okamuranus TOKIDA in U937 cells. Int. J. Biol. Macromol. 2007, 41, 221-226. [CrossRef] [PubMed]

20. Chevolot, L.; Foucault, A.; Chaubet, F.; Kervarec, N.; Sinquin, C.; Fisher, A.-M.; Boisson-Vidal, C. Further data on the structure of brown seaweed fucans: Relationships with anticoagulant activity. Carbohydr. Res. 1999, 319, 154-156. [CrossRef]

21. Saad, O.M.; Leary, J.A. Delineating Mechanisms of Dissociation for Isomeric Heparin Disaccharides Using Isotope Labeling and Ion Trap Tandem Mass Spectrometry. J. Am. Soc. Mass Spectrom. 2004, 15, 1274-1286. [CrossRef] [PubMed]

22. Wang, J.; Zhang, Q.; Zhang, Z.; Li, Z. Antioxidant activity of sulfated polysaccharide fractions extracted from Laminaria japonica. Int. J. Biol. Macromol. 2008, 42, 127-132. [CrossRef] [PubMed]

23. Halliwell, B.; Gutteridge, J.M.C.; Aruoma, O.I. The deoxyribose method: A simple "test-tube" assay for determination of rate constants for reactions of hydroxyl radicals. Anal. Biochem. 1987, 165, 215-219. [CrossRef]

24. Shon, M.-Y.; Kim, T.-H.; Sung, N.-J. Antioxidants and free radical scavenging activity of Phellinus baumii (Phellinus of Hymenochaetaceae) extracts. Food Chem. 2003, 82, 593-597. [CrossRef]

25. Zhu, X.; Lee, H.G.; Casadesus, G.; Avila, J.; Drew, K.; Perry, G.; Smith, M.A. Oxidative imbalance in Alzheimer's disease. Mol. Neurobiol. 2005, 31, 205-217. [CrossRef]

26. Wade, C.R.; Jackson, P.G.; Highton, J.; van Rij, A.M. Lipid peroxidation and malondialdehyde in the synovial fluid and plasma of patients with rheumatoid arthritis. Clin. Chim. Acta 1987, 164, 245-250. [CrossRef]

27. Wang, J.; Zhang, Q.; Zhang, Z.; Song, H.; Li, P. Potential antioxidant and anticoagulant capacity of low molecular weight fucoidan fractions extracted from Laminaria japonica. Int. J. Biol. Macromol. 2010, 46, 6-12. [CrossRef] [PubMed]

28. Jin, W.; Zhang, W.; Liu, G.; Yao, J.; Shan, T.; Sun, C.; Zhang, Q. The structure-activity relationship between polysaccharides from Sargassum thunbergii and anti-tumor activity. Int. J. Biol. Macromol. 2017, 105, 686-692. [CrossRef] [PubMed]

29. Yen, G.C.; Chen, H.Y. Antioxidant Activity of Various Tea Extracts in Relation to Their Antimutagenicity. J. Agric. Food Chem. 1995, 43, 27-32. [CrossRef]

30. Shimada, K.; Fujikawa, K.; Yahara, K.; Nakamura, T. Antioxidative properties of xanthan on the autoxidation of soybean oil in cyclodextrin emulsion. J. Agric. Food Chem. 1992, 40, 945-948. [CrossRef]

(C) 2018 by the authors. Licensee MDPI, Basel, Switzerland. This article is an open access article distributed under the terms and conditions of the Creative Commons Attribution (CC BY) license (http://creativecommons.org/licenses/by/4.0/). 